\title{
Review
}

Stephen G. Bown*

\section{Photodynamic therapy for cancer of the pancreas - the story so far}

\author{
Photodynamische Therapie des Pankreaskarzinoms - Bisherige Forschungsergebnisse
}

DOI 10.1515/plm-2016-0001

Received January 28, 2016; revised February 29, 2016; accepted

March 1, 2016

\begin{abstract}
Background and objective: Pancreatic cancer has long been a leading cause of cancer death. Few patients are suitable for surgery and for those who are not, the response to treatment is generally poor. No more than about 10\% survive for more than a year. Recent research has focused on focal treatment for local disease control. This review covers the development of one of the most promising options, photodynamic therapy (PDT).

Methods: This review covers pre-clinical and clinical studies. Laboratory work was designed to understand the effect of PDT on the normal pancreas and surrounding tissues and on transplanted cancers in the hamster pancreas to ensure safety prior to clinical application. Essentially all clinical studies have been undertaken in University College Hospital, London. Phase-I studies used the photosensitisers mTHPC and verteporfin in patients with localised but inoperable cancers.
\end{abstract}

Results: Laboratory results showed that normal pancreas, bile duct, liver, stomach and major blood vessels could tolerate PDT without any unacceptable effects on the structure and function of these organs. Necrosis that healed safely was documented in transplanted cancers. The clinical trials showed that focal necrosis could be produced in inoperable cancers with acceptable levels of complications, but considerable refinements of treatment delivery and monitoring are required before the technique will be ready for assessment in controlled clinical trials.

\footnotetext{
*Corresponding author: Stephen G. Bown, Emeritus Professor of Laser Medicine and Surgery, Division of Surgery and Interventional Science, Research Department of Tissue and Energy, Wing 2.4 Cruciform Building, University College London, Gower St., London WC1E 6BT, UK, e-mail: s.bown@ucl.ac.uk
}

Conclusions: PDT is showing promise for the minimally invasive treatment of localised pancreatic cancers, but it is still at an early stage of development. Much more work will be necessary to optimise techniques for applying PDT to these cancers and for combining it with other therapeutic options such as chemotherapy.

Keywords: biology of photodynamic therapy (PDT); translational studies of PDT for pancreatic cancer.

\section{Zusammenfassung}

Hintergrund und Zielsetzung: Bauchspeicheldrüsenkrebs gehört seit langem zu den am häufigsten zum Tode führenden Krebserkrankungen. Nur wenige Patienten sind für einen chirurgischen Eingriff geeignet und die, die es nicht sind, haben in der Regel eine schlechte Prognose. Nicht mehr als etwa 10\% überleben für mehr als ein Jahr. Die neuere Forschung hat sich bei der Krankheitsbekämpfung auf fokale Behandlungsformen konzentriert. Die vorliegende Arbeit konzentriert sich auf die Entwicklung einer der vielversprechendsten Optionen, die Photodynamische Therapie (PDT).

Methoden: Das vorliegende Review umfasst sowohl präklinische als auch klinische Studien. Laboruntersuchungen wurden durchgeführt, um zunächst die Wirkung der PDT auf die normale Bauchspeicheldrüse und das umgebende Gewebe sowie auf transplantierte Tumoren im Hamstermodell zu verstehen, um so die Sicherheit im Vorfeld klinischer Anwendungen zu gewährleisten. Im Wesentlichen wurden alle klinischen Studien im University College Hospital, London durchgeführt. In Phase-I-Studien wurden die Photosensibilisatoren mTHPC und Verteporfin bei Patienten mit lokal begrenztem, aber inoperablem Krebs angewendet.

Ergebnisse: Die Laborergebnisse zeigten, dass normales Gewebe von Bauchspeicheldrüse, Gallengang, Leber, und Magen sowie große Blutgefäße eine PDT ohne 
inakzeptable Auswirkungen auf die Struktur und Funktion dieser Organe tolerieren kann. Nekrosen, die sicher heilten, wurden in transplantierten Tumoren dokumentiert. Die klinischen Studien haben gezeigt, dass fokale Nekrosen bei inoperablen Tumoren mit tolerablen Komplikationen erzeugt werden können, aber eine erhebliche Verbesserung der Behandlung und Überwachung erforderlich sind, bevor die Technik in kontrollierten klinischen Studien weiter beurteilt werden kann.

Schlussfolgerungen: Die PDT stellt eine vielversprechende minimal-invasive Behandlungsoption bei lokalisiertem Bauchspeicheldrüsenkrebs dar, befindet sich aber noch in einem frühen Entwicklungsstadium. Mehr Forschungsarbeit ist notwendig, um die für die PDT erforderlichen Techniken für diese Krebsart zu optimieren und die PDT mit anderen therapeutischen Optionen, wie der Chemotherapie, kombinieren zu können.

Schlüsselwörter: Biologie der Photodynamischen Therapy (PDT); translationale Studien zur PDT von Bauchspeicheldrüsenkrebs.

\section{Clinical background}

Pancreatic cancer has long been one of the top 10 leading causes of cancer deaths, and comes in the top 5 in the UK and USA. The prognosis is poor with a 1-year survival rate of no more than $10 \%$. In the absence of metastases at presentation, the median survival is $6-10$ months although for those who have metastatic disease at presentation, the median survival is $<6$ months [1]. In specialised treatment centres, around $10 \%$ of patients may have resectable tumours at the time of diagnosis, but in reports reviewing larger populations, the number suitable for potentially curative surgery falls to as low as $3 \%$. Even after successful resection, the median survival is no more than $10-20$ months with few series showing a 5-year survival beyond about $10 \%$. In skilled hands, the operative mortality can be close to zero, but pancreatectomy is a major procedure with a prolonged recovery period. The main non-surgical options are chemotherapy, radiotherapy, or some combination of the two. In Europe and North America, the chemotherapy agent used most frequently is gemcitabine. A UK phase-III multicentre randomised clinical trial (over 500 patients) comparing gemcitabine alone or in combination with capecitabine for patients with advanced pancreatic cancer showed a trend towards improved survival benefit with combination therapy (median 7.1 vs. 6.2 months) but the improvement from adding the capecitabine was marginal [2]. More recently, the French randomised chemotherapy study of FOLFIRINOX (fluorouracil, leucovorin, irinotecan and oxaliplatin) versus gemcitabine, showed a significantly improved survival in the FOLFIRINOX group (median 11.1 vs. 6.8 months), but there was a high price to pay in terms of the toxicity of treatment [3]. So far, trials of biological agents such as vascular endothelial growth factor inhibitors in advanced disease have been largely disappointing. These disheartening results have given rise to the idea of looking for minimally invasive treatments capable of local destruction of tumour tissue with low morbidity that might have a place in the overall management of this unpleasant disease.

\section{Focal therapy}

The pancreas is located deep inside the body and is surrounded by many vital structures, particularly the stomach, duodenum, common bile duct, liver and major blood vessels such as the hepatic artery, portal vein, descending aorta and inferior vena cava. Any local treatment to a tumour in the pancreas must be sufficiently well localised not to extend to surrounding tissues or be adequately tolerated by these tissues.

The simplest options are techniques for delivering heat using a probe that can be inserted directly into the pancreas under image guidance. Early studies used a laser fibre for doing this [4], as had been shown to be effective in other organs [5], but in recent years, radiofrequency ablation (RFA) has been the preferred option for interstitial thermal treatment of tumours in solid organs such as the liver and lungs, where it is now well established in routine use [6]. However, thermal ablation damages connective tissue like collagen, which reduces the mechanical integrity of hollow organs like the duodenum and bile duct, with the consequent risk of perforation if treatment extends to these organs. In normal pancreas, thermal ablation heals safely, but only as long as it does not extend to the surface of the gland, where there might be a risk of fistula formation.

The technique that has been studied most is photodynamic therapy (PDT). PDT is a way of producing localised tissue necrosis with light after prior administration of a photosensitising agent in the presence of oxygen. The cytotoxic intermediary is thought to be singlet oxygen. As the biological effect is photochemical rather than thermal and there is no significant change in tissue temperature during light delivery, there is little damage 
to connective tissues such as collagen and elastin, which helps to maintain the mechanical integrity of hollow organs like the gastrointestinal tract and major blood vessels $[7,8]$.

Another major attraction is that the light used is in the visible and near-infrared part of the optical spectrum and so is not ionising. This means that PDT does not carry the risk of cumulative toxicity associated with radiotherapy. Once a PDT-treated area has healed, it can be treated with PDT again, if clinically indicated. PDT can also be used to treat areas which have already received the maximum safe dose of radiotherapy.

Much of the early interest in PDT centred around the selective uptake and retention of photosensitising drugs in cancers compared with the surrounding normal tissue in which the cancer arose, which raised the possibility of selective destruction of cancers. There is some selectivity of uptake. This is rarely enough to make truly selective tumour necrosis possible, although some selectivity has been shown experimentally with PDT alone [9] and combining PDT with a radioprotective agent [10]. However, if necrosis of normal tissue heals safely without any unacceptable loss of structure or function, then truly selective necrosis of tumour is not essential [11].

There are other minimally invasive techniques that could be considered:

a. Cryotherapy. This produces localised necrosis, but it is difficult to deliver a cryogen to the pancreas as the delivery tubes are too large for passage through needles suitable for inserting into the pancreas. However, it has been reported [12].

b. Local injection of chemotherapy drugs. This has potential, but it is difficult to control exactly where the drug would go if injected into a solid tumour, especially ones like pancreatic cancers, which are notoriously hard [13].

c. Brachytherapy (interstitial insertion of radioactive sources). This has worked well in the prostate either with a high-dose source inserted sequentially into many sites for a short period or multiple low-dose seeds inserted permanently, but would provide practical difficulties in the pancreas as many needles would be required. Nevertheless, it has been reported [14].

d. High intensity focused ultrasound (HIFU). This has been used quite extensively in China and other East Asian countries, sometimes in combination with chemotherapy and radiotherapy and can provide good pain relief in many patients [15].

However, PDT seems the most promising technique, with RFA also a realistic option.

\section{Pre-clinical studies of photodynamic therapy}

\subsection{Pre-clinical photodynamic therapy in the normal pancreas and adjacent organs}

With so many vital organs in the vicinity of the pancreas, the first priority was to understand what PDT did to normal pancreas and the surrounding organs. Many papers have been published on this topic from our group, mainly in Syrian golden hamsters, using a variety of photosensitisers including aluminium disulphonated phthalocyanine, 5-aminolaevulinic acid (ALA), meso-tetrahydroxylphenyl chlorin (mTHPC), and verteporfin, dating back as far as 1991 [16-18]. The results with all were broadly similar. Some sealed and free perforations were seen in the duodenum, thought to be due to the very thin wall of the hamster duodenum. In all the other organs tested, pancreas, stomach, duodenum, liver, common bile duct, aorta and inferior vena cava, necrosis was seen but the treated areas healed safely with no unacceptable effects on structure or function.

\subsection{Pre-clinical photodynamic therapy in transplanted cancers}

The encouraging studies on normal tissues were followed by studies on transplanted cancers. PDT effects depend closely on the drug dose, the light dose and the time interval between drug and light delivery. There are also considerable differences between organs, so meaningful studies required pancreatic cancers to be transplanted directly into the pancreas of hamsters. Studies on cancers growing in experimentally convenient sites such as under the skin do not give the most important information on how a cancer growing in its organ of origin will respond. These studies have been undertaken by our group in London using three different photosensitisers (phthalocyanine, mTHPC, ALA) $[9,19,20]$. Other groups have undertaken similar studies with porfimer sodium and pheophorbide A [21].

The first steps were pharmacodynamic studies to determine the drug-light interval that gave the best ratio of tissue concentration of drug in the cancer to that in the adjacent normal pancreas. This varied considerably from a few hours to several days, depending on the photosensitiser used. Using the optimum drug-light interval for each photosensitiser - as with the studies on normal animals the biological effects on transplanted cancers were 
broadly similar with all the photosensitisers investigated. Necrosis could be produced in the cancer with a small degree of selectivity between cancer and normal pancreas [9]. A randomised study using ALA as the photosensitising agent showed a significantly increased survival time in PDT-treated tumour bearing animals compared with untreated controls [20]. Comparable randomised studies have not been undertaken with other photosensitisers.

\section{Clinical studies of photo- dynamic therapy for cancer of the pancreas}

\subsection{First clinical trial}

\subsubsection{Methods}

The pre-clinical results were considered sufficiently encouraging to justify a phase-I clinical trial. This was approved by the Ethics Committee at University College Hospital, London, UK. The first patient was treated in 1996 and the first full publication appeared in 2002 [22]. The photosensitiser chosen was mTHPC (Foscan ${ }^{\circledR}$ ). This was the agent shown to be most effective in animal studies, although it was recognised that it was associated with prolonged skin and eye photosensitivity. Sixteen patients with inoperable adenocarcinoma $(2.5-6 \mathrm{~cm}$ in diameter), localised to the head of the pancreas were studied. In 14 cases, the main contraindication for surgery was vascular involvement of the cancer. The two with the smallest cancers were in too poor a general condition to undertake major surgery. All 16 patients presented with obstructive jaundice, which was relieved by biliary stenting prior to further treatment. mTHPC was administered intravenously $(0.15 \mathrm{mg} / \mathrm{kg})$ followed by direct illumination of the tumour 3 days later. For light delivery, needles (up to 6 per patient) were inserted into the tumour percutaneously under ultrasound guidance and correct positioning in the cancer confirmed on computed tomography (CT) scanning. Thin laser fibres $(0.4 \mathrm{~mm}$ core diameter, plain cut tip) could then be passed through to the distal end of the needles, and the needles withdrawn about $3 \mathrm{~mm}$ over the fibres, leaving the tips of the fibres in direct contact with the tumour tissue. Light from a laser at $652 \mathrm{~nm}$ was delivered via a beam splitter so up to four fibres could be activated simultaneously (100 mW, $20 \mathrm{~J}$ per site). These procedures were undertaken under sedation and local anaesthetic and were well tolerated (Figure 1).

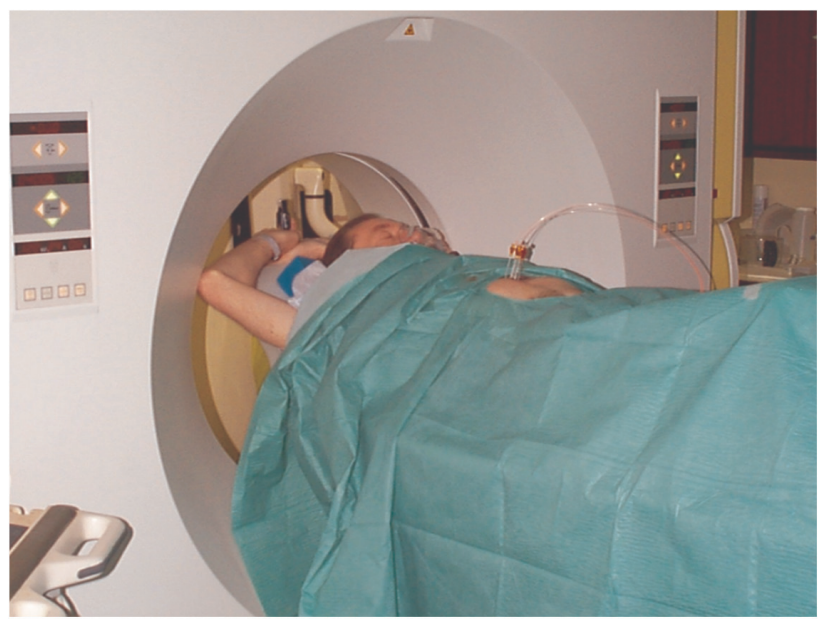

Figure 1: Percutaneous, interstitial photodynamic therapy for cancer of the pancreas. Four needles were inserted into the pancreas under ultrasound guidance and their positions checked with a computerised tomography (CT) scan. A thin laser fibre was passed through each needle to deliver red light directly to the cancer. (Reproduced, with permission, from [22].)

\subsubsection{Results}

All patients had some pain after the procedure, most requiring opiates for a few days, but most were able to resume oral intake after about $48 \mathrm{~h}$. None developed pancreatitis and there were no treatment related deaths. Fourteen patients were home $<10$ days after light delivery, with adequate oral intake and feeling comfortable. Of the other two, one had a major bleed, thought to be due to tumour involvement of the gastroduodenal artery, controlled by radiological embolization and the other had ongoing pain and anorexia and required a gastrostomy for feeding [22].

In all cases, contrast-enhanced CT scans taken 3-5 days after PDT showed new areas of non-enhancement, interpreted as zones of PDT-induced necrosis (Figure 2). This was confirmed on biopsy in one case. The volume of necrosis ranged from 9 to $60 \mathrm{~cm}^{3}$. The median radius of necrosis around the site of each treatment fibre was $9 \mathrm{~mm}$, but this varied over the range of 7-11 $\mathrm{mm}$. There were only three cases in which no definite cancer could be seen and three others in whom only tiny areas of cancer could be seen in the pancreas in the early post-PDT scans. In most cases, the treated area healed safely, but tumour often regrew from the edges of the treated area. Treatable complications included cholangitis and duodenal obstruction. Full details are given in the original publication [22]. This was a phase I/II study, so the treatment parameters were conservative and it was not surprising that the full extent of tumour was not treated. The survival time after PDT ranged from 4 to 30 months (median 9.5 months, 

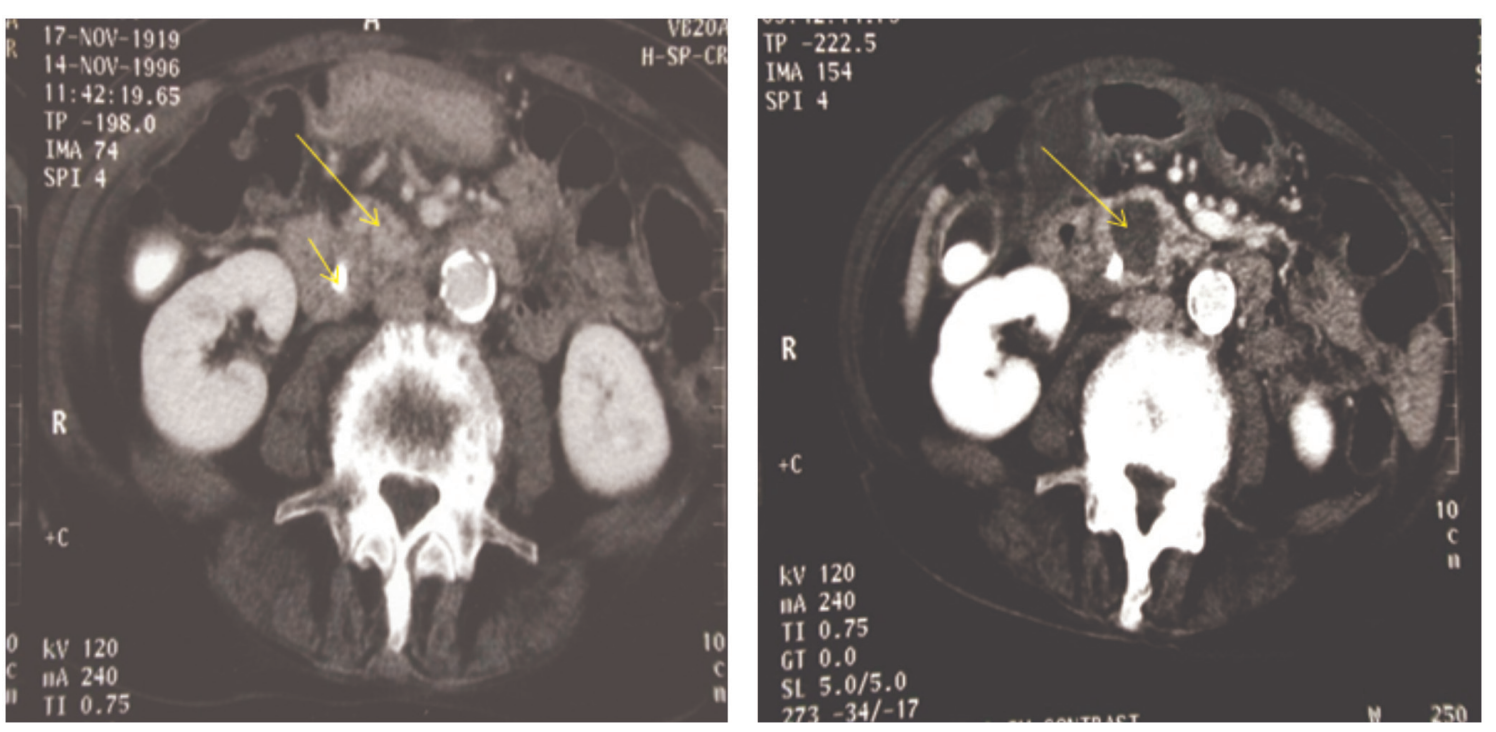

Figure 2: Contrast-enhanced computerised tomography (CT) scans of a carcinoma of the pancreas. Left: Prior to photodynamic therapy (PDT) showing a 2.8-cm carcinoma in the head of the pancreas (long arrow). This patient had a plastic biliary stent in place at the time of treatment (short arrow). Right: 4 days after PDT, showing a large new area of non-enhancement in the tumour area (long arrow). (Reproduced, with permission, from [22].)

one patient being alive at 31 months), with most patients receiving PDT 2-3 months after their initial diagnosis. Only three patients spent more than $20 \%$ of their survival time after PDT in hospital. Three patients had chemotherapy when they had recovered from PDT. They survived 11, 12, and 15 months after PDT [22].

This study was the first clinical report of PDT for pancreatic cancer. No patients were cured, but most had a short stay in hospital and their quality of life after PDT was good. It showed that PDT can produce localised necrosis in pancreatic cancers and although some serious complications were seen, they were treatable and explicable, so it was thought that in future it should be possible to avoid the situations in which these arose.

\subsection{Recent clinical studies}

Despite these encouraging early results, it was several years before funding was raised to take this work forward. However, two further studies have now been published from our group, using the photosensitiser verteporfin (Visudyne $^{\circledR}$ ) in a collaboration between University College London, Harvard Medical School and Dartmouth College $[23,24]$. Verteporfin has the major advantage that the drug-light interval required is only $60-90 \mathrm{~min}$ rather than the 3 days required for mTHPC. This is much more convenient for patients and clinical staff and means that any risk of skin and eye photosensitivity is reduced to a few days rather than several weeks. Further, the wavelength of light required is $690 \mathrm{~nm}$, which has better penetration of living tissue than the $652 \mathrm{~nm}$ used with mTHPC.

\subsubsection{Dose-ranging study using the photosensitiser verteporfin}

The recent publications were both based on a new study undertaken in the same hospital in London as the original work. The patient selection and basic PDT protocol was essentially the same as in the original study [22]. Patients with localised pancreatic cancers considered inoperable, usually due to vascular involvement, were recruited. However, there was considerable refinement of the light dosimetry and imaging. As before, light $(690 \mathrm{~nm}$ for verteporfin) was delivered using laser fibres passed through needles inserted percutaneously under ultrasound and CT guidance but for the first 13 patients, only a single fibre was used. These were fibres with a 1-cm diffuser tip rather than the plain cut fibres used previously. It had been noted in the earlier study that there appeared to be a considerable variation in the volume of necrosis around each treatment site (radius of necrosis around each treatment site varied from 7-11 $\mathrm{mm}$ ). Using multiple fibres, it was difficult to be sure how far apart the actual treatment sites for each fibre were and consequently how much overlap of effect there was from the light delivered to adjacent fibres. The new study initially used just a single fibre, starting 
with a light dose of $5 \mathrm{~J}$ and doubling this after every three patients until there was a maximum diameter of necrosis of at least $12 \mathrm{~mm}$ in all three patients in a group. This was achieved when the dose reached $40 \mathrm{~J}$. The total volume of necrosis in each patient was estimated by segmentation of serial slices of contrast-enhanced CT scans taken a few days after PDT. The results were expressed as volume of necrosis, as few necrotic zones were truly spherical. The necrosis volumes for individual patients with valid results are shown in Table 1. The striking result was that there was considerable variation in the volume of necrosis around the treatment site in different patients treated with the same light dose, particularly at 20 and $40 \mathrm{~J}$ [23], comparable to the variation commented on in the original study [22]. Unlike the original study, this study did not attempt to treat enough sites in the cancer to destroy it all. It was clear from the original study that in the present state of knowledge, there was no prospect of PDT curing these cancers and all patients were made aware of this, although the PDT may have had some palliative benefit. Undoubtedly, it helped the patient who was found to be operable after PDT, although it is unlikely that this could have been predicted.

The last two patients were treated with multiple fibres. There was a particularly remarkable, although anecdotal, observation in this study. One patient was included as his CT scan suggested that the tumour abutted the superior mesenteric artery, making him inoperable. One month after PDT, a repeat CT scan showed a clear tissue plane between the cancer and the tumour, so making it operable.

Table 1: Volume of photodynamic therapy (PDT) induced necrosis, measured by segmentation of contrast-enhanced computerised tomography (CT) scans taken 5 days after PDT in 12 individual patients treated with a single $1-\mathrm{cm}$ diffuser tipped fibre.

\begin{tabular}{lrrrr}
\hline & \multicolumn{4}{c}{ Delivered energy (J) } \\
\cline { 2 - 5 } & $\mathbf{5}$ & $\mathbf{1 0}$ & $\mathbf{2 0}$ & $\mathbf{4 0}$ \\
\hline Volume of necrosis for & 0.00 & 0.96 & 0.34 & 5.17 \\
each of the 12 individual & 0.00 & 0.43 & 2.37 & 2.61 \\
patients $\left(\mathrm{cm}^{3}\right)$ & 0.00 & 0.00 & 0.72 & 2.67 \\
\hline
\end{tabular}

For each energy dose group $(5,10,20$ and $40 \mathrm{~J})$, three patients were treated. No necrosis was seen in the three patients who were treated with $5 \mathrm{~J}$. For those treated with 10,20 or $40 \mathrm{~J}$, there was a marked variation in the extent of necrosis within each energy group. This poor correlation between energy delivered and volume of necrosis is illustrated by another example. In a further patient treated with two fibres, each with $1 \mathrm{~cm}$ diffuser tips, with $40 \mathrm{~J}$ delivered down each fibre, the volume of necrosis was $5.3 \mathrm{~cm}^{3}$. This value was very similar to the first patient in the $40 \mathrm{~J}$ energy group, treated with a single fibre, shown here with a determined volume of necrosis of $5.17 \mathrm{~cm}^{3}$.
He subsequently underwent a Whipple's resection of the pancreas and duodenum and the surgical margins proved to be free of tumour. The likely explanation is that the tumour was immediately adjacent to the artery but not actually invading it. The area of PDT necrosis in another part of the cancer healed by shrinking, so pulling the tumour away from the artery, making it clear on the follow-up CT scan that surgery was feasible. He was well for a further 3 years after surgery before recurrent cancer was detected and he was started on chemotherapy.

\subsubsection{Contrast-enhanced CT scanning for predicting the extent of necrosis}

The most recent publication [24] set out to determine the dominant factors affecting the extent of necrosis around treatment sites in the verteporfin study. This is one of the most important aspects of dosimetry when the treated tissue is left to heal in situ rather than being removed surgically. Clinically, the aim should always be to treat the entire tumour with as little damage to adjacent normal tissues as possible. With invasive cancers, it is often a challenge to define exactly how far a cancer extends as it is difficult to detect a few cancer cells invading apparently normal areas. Often, the best one can do is to estimate how far a cancer is likely to have spread beyond what is detectable on imaging such as $\mathrm{CT}$ and magnetic resonance imaging (MRI), based on experience of previous patients with similar cancers. Wherever possible, a surgeon will include a margin of apparently normal tissue, typically a few $\mathrm{mm}$, in the hope of removing these previously undetected cancer cells, but it is always a compromise between having the best chance of removing all the cancer and minimizing the disruption to structure and function of the tissue left behind.

A surgeon has precise control of the excision margins of tissue he/she removes and the pathologist can examine the surgical specimen to see if the margins are clear of cancer. No pancreatic cancer patient will have surgery unless there is a good chance that it will be feasible to remove the entire cancer. As described above, normal pancreas and most of the surrounding tissues can tolerate PDT without any unacceptable loss of structure or function. This is one of the major attractions of PDT as it can sometimes treat small areas of cancer involving vital structures without impairing the function of those structures. However, when light is delivered to the pancreas interstitially under image guidance, reports from the two studies described above showed how unpredictable the extent of the PDT effect can be when the treatment parameters are 
fixed (drug dose, drug-light interval and light dose) but are not related to the individual cancers being treated. Nevertheless, there is usually a sharp cut-off between viable tissue and PDT-induced necrosis [17]. The problem lies in ensuring that the cut-off line is in the right place: all the cancer in the necrotic zone and nothing else in the necrotic zone that cannot tolerate PDT. One problem that has been encountered clinically is related to blood vessels. Normal and atheromatous arteries can tolerate PDT without rupture or thrombosis $[8,25]$, but large arteries that are directly invaded by cancer are at risk of perforation and this was seen in two cases in the first clinical study [22].

The aim of the recent study [24] was to look for ways in which clinically available information could be used for more accurate prediction of the extent of necrosis that PDT would produce in treated cancers. There was a particular focus on detailed analysis of CT imaging. By comparing CT scans before and shortly after administration of an intravenous contrast agent (venous phase scan), it is possible to assess the volume of blood in the cancer and surrounding tissue. This influences the penetration depth of the therapeutic light and hence the volume of necrosis. The study correlated variations in the venous blood volume with the documented extent of PDT necrosis on scans taken a few days after PDT. The analysis and full results are described in detail in the original publication [24]. There is a strong negative correlation between the contrast-derived venous blood content and the volume of PDT necrosis $\left(R^{2}=0.87\right)$. This suggests that the optical attenuation produced by venous blood is a dominant factor in the treatment response to PDT. This study used a fixed drug dose and drug-light interval, so no comment could be made on the effect of varying the tissue concentration of photosensitiser. It has been recognised for many years that PDT is a threshold effect and that the threshold for a tissue effect depends on the product of the drug concentration and the absorbed light energy at every point, as well as the presence of an adequate concentration of oxygen, although the latter is rarely the limiting factor.

The fundamental achievement of this paper was to show that the distribution of light within individual cancers, as determined by the distribution of blood, is critical and that it is not possible to predict the extent of PDT necrosis based just on the administered drug and light doses, although these are, of course, also important. Further quantitative analysis showed a strong correlation between the volume of necrosis calculated using the CT surrogate estimate of venous blood content and standard light modelling tools and that measured by post-treatment $\mathrm{CT}$, with an $\mathrm{R}^{2}=0.91$ [24]. This could represent an important breakthrough in PDT for pancreatic cancer and could facilitate light dose administration tailored to individual cancers with significantly less effort than using invasive or time consuming light dosimetry measurements. The concept of using perfusion CT has also been explored as a way of predicting the distribution of photosensitiser in pre-clinical studies in a rabbit orthotopic pancreatic cancer model [26].

\section{The future}

\subsection{New approaches to pancreatic photodynamic therapy}

\subsubsection{Light delivery using endosonography}

Up to the present, light has been delivered to the pancreas using laser fibres passed through needles inserted percutaneously under guidance from ultrasound and CT scanning. This means that the needles have to pass through the abdominal skin, underlying muscle, peritoneum and both the front and back walls of the stomach to get to the pancreas. If multiple sites in the cancer need to be treated, this requires multiple needle insertions, with the associated risks of internal bleeding (which was seen in two of the patients in the first study) and of tumour cells being seeded along the needle track as the needle tip will be directly in tumour tissue (a small risk, but a serious complication). A proposed new approach is to insert the fibres endoscopically. With an ultrasound probe built into an endoscope, the pancreas can be imaged directly through the wall of the stomach or duodenum (endosonography). The laser fibre could then be passed through the operating channel of the instrument directly into a tumour in the pancreas (endoscopic ultrasound-guided PDT). This would be inherently safer than the percutaneous approach, although only one fibre could be used at a time and treating more than one area would require repositioning. This endoscopic technique has been shown to produce necrosis in the pancreas of normal pigs, the laser fibre being passed through a thin aspiration needle in the biopsy channel of the echoendosdope [27]. Oncological treatments delivered using endoscopic ultrasound are reviewed by Kaplan [13].

\subsubsection{Combining photodynamic therapy with other treatments}

Up to the present, there has been reluctance to give chemotherapy within a month of PDT because of concerns 
that the combination might be too toxic, but there is no fundamental reason why this should be the case. New studies with less time between the two are planned. Likewise, consideration could be given to combining PDT with radiotherapy.

\subsubsection{Immunological stimulation by photodynamic therapy}

It is recognised that in the current state of the art, PDT is a local treatment for cancer of the pancreas and cannot control disease that has spread to other organs. There is evidence that PDT can stimulate an immunological response to cancer and this is an area of intense scientific research [28]. However, this is not yet sufficiently understood to be of value in clinical practice.

\subsubsection{Nanoscale drug delivery vehicles to facilitate multimodal cancer therapy}

A very recent publication introduces a photoactivatable, multi-inhibitor nanoliposome (PMIL) that imparts lightinduced cytotoxicity in synchrony with a photo-initiated and sustained release of inhibitors that suppress tumour regrowth and treatment escape signalling pathways [29]. In mouse studies, near-infrared tumour illumination after prior intravenous administration of PMIL triggers photodynamic damage of tumour cells and microvessels and simultaneously initiates release of XL184 inside the tumour. A single treatment can achieve prolonged tumour reduction and suppress metastatic escape in an orthotopic pancreatic tumour model. This approach offers new prospects for cancer therapy by enabling spatiotemporal control of drug release while reducing systemic drug exposure and the associated toxicities [29].

\subsection{Early diagnosis}

\subsubsection{Cysts}

As outlined above, pancreatic cancer is a devastating disease that is most often diagnosed late, with few effective treatment strategies. The prognosis could be improved with better diagnostic and treatment options for early disease and for precursor lesions such as cysts. Cystic lesions of the pancreas are an emerging health issue, being present without symptoms in up to $13.5 \%$ of patients undergoing abdominal MRI scans for reasons unrelated to the pancreas. Currently, the management of the subgroup of patients with mucinous cystic tumours (a small proportion of which may develop into cancers) relies on either surveillance by non-invasive imaging or surgical resection. There is a need for minimally invasive ablative treatments such as PDT to reduce the need for major surgery or the inconvenience, anxiety and costs associated with long-term imaging surveillance. One case of PDT for intraductal papillary mucinous neoplasm (IPMN) of the pancreas has been reported using the photosensitiser porfimer sodium. Light was delivered to the tumour by inserting a diffuser fibre directly into the pancreatic duct at endoscopic retrograde cholangiopancreatography. Both the symptoms and imaging and biopsy findings of the IPMN resolved after PDT, although metastatic cancer was diagnosed 2 years later [30].

\subsubsection{Other pancreatic tumours}

Adenocarcinomas are by far the commonest cancers of the pancreas and arise in exocrine cells (cells that produce digestive enzymes). However, cancer can arise in other cells in the pancreas, such as those in areas known as the islets of Langerhans that produce hormone-like substances such as insulin. These cancers (known as neuroendocrine tumours) are rare, but often produce symptoms much earlier than the common cancers due to the effects of excess levels of hormones, and so the tumour volume can be quite small without metastases at the time of diagnosis. The main difficulty is often actually locating them, but if they can be found they could be suitable for ablation with PDT.

\subsubsection{Biomarkers}

Biomarkers are substances characteristic of specific diseases or groups of diseases that can be detected in blood or tissue [31]. The search for biomarkers in well patients as an indication of likely future disease in individuals known to be at increased risk for specific diseases or just for screening in the general population is a hot research topic. It is of particular importance in those thought to have a high risk of developing cancer and also for monitoring cancer treatment. In the future, the combination of sensitive biomarkers and less invasive treatments like PDT could help to find and treat pancreatic cancers at a stage when cure may be possible. 


\section{Conclusions}

It is 25 years since PDT was first considered for treating cancer of the pancreas and 20 years since the first patient was treated. Even on medical research standards, this is slow progress, but those developing other treatments for this devastating disease have not done much better. We can now say that PDT can produce localised necrosis in inoperable pancreatic cancers using a minimally invasive technique with safe healing of the treated area. There have been complications, but there has been no treatmentrelated mortality and we now understand the treatment better and so are likely to be able to avoid many of these problems in the future. The challenge is to be able to treat an entire cancer and at present we can only offer a local treatment. However, the importance of good local control should not be minimised. It may provide significant survival benefit and enhanced quality of life to patients with advanced metastatic disease. New approaches such as combining PDT with chemotherapy and/or radiotherapy, detecting and treating earlier disease and enhancing the immuno-stimulatory effect of PDT may improve the prognosis. Nevertheless, all these options must be refined so they are used to optimum effect and then assessed in randomised clinical trials comparing the results with conventional therapy.

Conflict of interest statement: The author states no conflict of interest. He has read the journal's Publication Ethics and Publication Malpractice Statement available at the journal's website and hereby confirms that he complies with all its parts applicable to the present scientific work.

\section{References}

[1] Luo J, Xiao L, Wu C, Zheng Y, Zhao N. The incidence and survival rate of population-based pancreatic cancer patients: Shanghai Cancer Registry 2004-2009. PLoS One 2013;8(10):e76052.

[2] Cunningham D, Chau I, Stocken DD, Valle JW, Smith D, Steward W, Harper PG, Dunn J, Tudur-Smith C, West J, Falk S, Crellin A, Adab F, Thompson J, Leonard P, Ostrowski J, Eatock M, Scheithauer W, Herrmann R, Neoptolemos JP. Phase III randomized comparison of gemcitabine versus gemcitabine plus capecitabine in patients with advanced pancreatic cancer. J Clin Oncol 2009;27(33):5513-8.

[3] Conroy T, Desseigne F, Ychou M, Bouché O, Guimbaud R, Bécouarn Y, Adenis A, Raoul JL, Gourgou-Bourgade S, de la Fouchardière $C$, Bennouna J, Bachet JB, Khemissa-Akouz F, Péré-Vergé D, Delbaldo C, Assenat E, Chauffert B, Michel P, Montoto-Grillot C, Ducreux M; Groupe Tumeurs Digestives of Unicancer; PRODIGE Intergroup. FOLFIRINOX versus gemcitabine for metastatic pancreatic cancer. N Engl J Med 2011;364(19):1817-25.

[4] Steger AC. Interstitial laser hyperthermia for the treatment of hepatic and pancreatic tumours. Photochem Photobiol 1991;53(6):837-44.

[5] Steger AC, Lees WR, Walmsley K, Bown SG. Interstitial laser hyperthermia: a new approach to local destruction of tumours. Br Med J 1989;299(6695):362-5.

[6] Labori KJ, Schulz A, Drolsum A, Guren MG4, Kløw NE, Bjørnbeth BA. Radiofrequency ablation of unresectable colorectal liver metastases: trends in management and outcome during a decade at a single center. Acta Radiol Open 2015;4(7):2058460115580877.

[7] Barr H, Tralau CJ, Boulos PB, MacRobert AJ, Tilly R, Bown SG. The contrasting mechanisms of colonic collagen damage between photodynamic therapy and thermal injury. Photochem Photobiol 1987;46(5):795-800.

[8] Grant WE, Buonaccorsi G, Speight PM, MacRobert AJ, Hopper C, Bown SG. The effect of photodynamic therapy on the mechanical integrity of normal rabbit carotid arteries. Laryngoscope 1995;105(8 Pt 1):867-71.

[9] Chatlani PT, Nuutinen PJ, Toda N, Barr H, MacRobert AJ, Bedwell J, Bown SG. Selective necrosis in hamster pancreatic tumours using photodynamic therapy with phthalocyanine photosensitization. Br J Surg 1992;79(8):786-90.

[10] Bedwell J, Chatlani PT, MacRobert AJ, Roberts JE, Barr H, Dillon J, Bown SG. Enhanced tumour selectivity of photodynamic therapy in the rat colon using a radioprotective agent. Photochem Photobiol 1991;53(6):753-6.

[11] Bown SG. Photodynamic therapy for photochemists. Philos Trans A Math Phys Eng Sci 2013;371(1995):20120371.

[12] Niu L, Chen J, He L, Liao M, Yuan Y, Zeng J, Li J, Zuo J, Xu K. Combination treatment with comprehensive cryoablation and immunotherapy in metastatic pancreatic cancer. Pancreas 2013;42(7):1143-9.

[13] Kaplan J, Khalid A, Cosgrove N, Soomro A, Mazhar SM, Siddiqui AA. Endoscopic ultrasound-fine needle injection for oncological therapy. World J Gastrointest Oncol 2015;7(12):466-72.

[14] Yu YP, Yu Q, Guo JM, Jiang HT, Di XY, Zhu Y. Effectiveness and security of CT-guided percutaneous implantation of (125)I seeds in pancreatic carcinoma. Br J Radiol 2014;87(1039):20130642.

[15] Zhou Y. High-intensity focused ultrasound treatment for advanced pancreatic cancer. Gastroenterol Res Pract 2014;2014:205325.

[16] Nuutinen PJ, Chatlani PT, Bedwell J, MacRobert AJ, Phillips D, Bown SG. Distribution and photodynamic effect of disulphonated aluminium phthalocyanine in the pancreas and adjacent tissues in the Syrian golden hamster. $\mathrm{Br} J$ Cancer 1991;64(6):1108-15.

[17] Mikvy P, Messmann H, Pauer M, Stewart JC, Millson CE, MacRobert AJ, Bown SG. Distribution and photodynamic effects of meso-tetrahydroxyphenylchlorin (mTHPC) in the pancreas and adjacent tissues in the Syrian golden hamster. $\mathrm{Br}$ J Cancer 1996;73(12):1473-9.

[18] Ayaru L, Wittmann J, Macrobert AJ, Novelli M, Bown SG, Pereira SP. Photodynamic therapy using verteporfin photosensitization in the pancreas and surrounding tissues in the Syrian golden hamster. Pancreatology 2007;7(1):20-7. 
[19] Mikvy P, Messman H, MacRobert AJ, Pauer M, Sams VR, Davies CL, Stewart JC, Bown SG. Photodynamic therapy of a transplanted pancreatic cancer model using meta-tetrahydroxyphenylchlorin (mTHPC). Br J Cancer 1997;76(6):713-8.

[20] Regula J, Ravi B, Bedwell J, MacRobert AJ, Bown SG. Photodynamic therapy using 5 -aminolaevulinic acid for experimental pancreatic cancer - Prolonged animal survival. Br J Cancer 1994;70(2):248-54.

[21] Evrard S, Keller P, Hajri A, Balboni G, Mendoza-Burgos L, Damgé C, Marescaux J, Aprahamian M. Experimental pancreatic cancer in the rat treated by photodynamic therapy. $\mathrm{Br}$ J Surg 1994;81(8):1185-9.

[22] Bown SG, Rogowska AZ, Whitelaw DE, Lees WR, Lovat LB, Ripley P, Jones L, Wyld P, Gillams A, Hatfield AW. Photodynamic therapy for cancer of the pancreas. Gut 2002;50(4):549-57.

[23] Huggett MT, Jermyn M, Gillams A, Illing R, Mosse S, Novelli M, Kent E, Bown SG, Hasan T, Pogue BW, Pereira SP. Phase I/II study of verteporfin photodynamic therapy in locally advanced pancreatic cancer. Br J Cancer 2014;110(7):1698-704.

[24] Jermyn M, Davis SC, Dehghani H, Huggett MT, Hasan T, Pereira SP, Bown SG, Pogue BW. CT contrast predicts pancreatic cancer treatment response to verteporfin-based photodynamic therapy. Phys Med Biol 2014;59(8):1911-21.

[25] Mansfield RJ, Jenkins MP, Pai ML, Bishop CC, Bown SG, McEwan JR. Long-term safety and efficacy of superficial femoral artery angioplasty with adjuvant photodynamic therapy to prevent restenosis. Br J Surg 2002;89(12):1538-9.

[26] Elliott JT, Samkoe KS, Gunn JR, Stewart EE, Gardner TB, Tichauer KM, Lee TY, Hoopes PJ, Pereira SP, Hasan T, Pogue BW. Perfusion CT estimates photosensitizer uptake and biodistribution in a rabbit orthotopic pancreatic cancer model: a pilot study. Acad Radiol 2015;22(5):572-9.

[27] Yusuf TE, Matthes K, Brugge WR. EUS-guided photodynamic therapy with verteporfin for ablation of normal pancreatic tissue: a pilot study in a porcine model (with video). Gastrointest Endosc 2008;67(6):957-61.

[28] Korbelik M, Merchant S. Photodynamic therapy-generated cancer vaccine elicits acute phase and hormonal response in treated mice. Cancer Immunol Immunother 2012;61(9):1387-94.

[29] Spring BQ, Bryan Sears R, Zheng LZ, Mai Z, Watanabe R, Sherwood ME, Schoenfeld DA, Pogue BW, Pereira SP, Villa E, Hasan T. A photoactivable multi-inhibitor nanoliposome for tumour control and simultaneous inhibition of treatment escape pathways. Nat Nanotechnol 2016. doi: 10.1038/ nnano.2015.311.

[30] Topazian M, Zhong N, Baron TH, Vege SS, Wang KK. Photodynamic therapy of intraductal papillary mucinous neoplasm. Endoscopy 2012;44(2):213-5.

[31] Alemar B, Gregório C, Ashton-Prolla P. miRNAs as diagnostic and prognostic biomarkers in pancreatic ductal adenocarcinoma and its precursor lesions: a review. Biomark Insights 2015;10:113-24.

\begin{tabular}{|l|}
\hline Q1: \\
Please \\
update \\
Ref. [29] \\
\hline
\end{tabular}

